\title{
AVALIAÇÃO DAS EMISSÕES GASOSAS, PARÂMETROS DE QUALIDADE E DESEMPENHO DE CONSUMO DE UM MOTOR DE COMBUSTÃO INTERNA OPERANDO COM MISTURAS GASOLINA/ADULTERANTE EM DIFERENTES PROPORÇÕES
}

\author{
EVALUATION OF GAS EMISSIONS, QUALITY PARAMETERS AND CONSUMPTION \\ PERFORMANCE OF A SPARK IGNITION ENGINE OPERATING ON DIFFERENT GASOLINE- \\ ADULTERANT BLENDS
}

\author{
Luciano Zart Olanyk ${ }^{1}$, Waldir Nagel Schirmer ${ }^{2}$, Matheus Vitor Diniz Gueri ${ }^{3}$, Carmem Luisa Barbosa Guedes ${ }^{4}$, \\ Dionísio Borsato $^{5}$, Paulo Rogério Pinto Rodrigues ${ }^{6}$, Talita Pedroso Quessada ${ }^{7}$, Douglas Santos de Oliveira $^{8}$ \\ Engenheiro de Produção Mecânica. Mestre em Bioenergia. E-mail: lzrt@ hotmail.com \\ ${ }^{2}$ Doutor em Engenharia Ambiental . Professor adjunto do curso de Engenharia Ambiental da Universidade Estadual do \\ Centro-Oeste - Irati-PR. E-mail: wanasch@ hotmail.com \\ Endereço para correspondência: Rodovia PR 153, km 7, Bairro Riozinho-PR. CEP 84500-000. \\ ${ }^{3}$ Graduando em Engenharia Ambiental pela Unicentro. E-mail: mgueri@hotmail.com \\ ${ }^{4}$ Doutora em Química Orgânica. Professora do curso de Química da Universidade Estadual de Londrina. \\ E-mail: carmenluisaguedes@gmail.com \\ ${ }^{5}$ Doutor em Ciências de Alimentos. Professor do curso de Química da Universidade Estadual de Londrina. \\ E-mail: dborsato@uel.br \\ ${ }^{6}$ Doutor em Química. Professor do curso de Química da Unicentro. E-mail: prprodrigues@gmail.com \\ ${ }^{7}$ Graduada em Química Tecnológica e Química Licenciatura. Mestre em Química. E-mail: talipq@hotmail.com \\ ${ }^{8}$ Graduado em Química. E-mail: douglas.santos.oliver@gmail.com
}

\begin{abstract}
RESUMO
O presente trabalho analisou os resultados de parâmetros de qualidade (curvas de destilação, teor de etanol, cor e aspecto e massa específica), desempenho (consumo mássico) e emissões dos poluentes atmosféricos monóxido de carbono $(\mathrm{CO})$, hidrocarbonetos $(\mathrm{HC})$ e óxidos de nitrogênio $\left(\mathrm{NO}_{\mathrm{x}}\right)$ para diversas misturas de combustíveis, formadas por gasolina A, $20 \% \mathrm{v} / \mathrm{v}$ de etanol, e diferentes teores de solvente alifático leve (o adulterante solvente para borracha). Os ensaios de destilação, teor de etanol, cor e aspecto e massa específica foram realizados conforme normas NBR 9619, NBR 13992, NBR 14954 e NBR 7148, respectivamente, e os ensaios de desempenho e de emissões foram realizados variando-se as cargas de um motor-gerador de $196 \mathrm{cc}$, entre 0 e $2000 \mathrm{~W}$. Os resultados dos ensaios mostraram que os parâmetros de qualidade avaliados não foram eficientes para revelar adulteração do combustível. A adição do adulterante resultou ainda no aumento do consumo mássico em 7\%, assim como no aumento das concentrações de CO e HC de 38 e $16 \%$, respectivamente, apesar da redução de $15 \%$ para o $\mathrm{NO}_{x}$
\end{abstract}

Palavras-chave: Adulteração da gasolina. Combustível. Curva de destilação.

\begin{abstract}
This paper investigated the results of quality parameters (distillation curves, ethanol content, color and appearance and density), performance (mass and specific) and emissions of air pollutants as carbon monoxide (CO), hydrocarbons (HC) and oxides of nitrogen (NOx) for different fuel blends formulated by gasoline, $20 \%$ $\mathrm{v} / \mathrm{v}$ ethanol content and different quantities of light aliphatic solvent (rubber solvent). Distillation, ethanol content, color and appearance and density assays were performed according to NBR 9619, NBR 13992, NBR 14954 and NBR 7148, respectively, and performance and emissions tests were performed in a motor-generator $196 \mathrm{cc}$ and variable charge between 0 and $2000 \mathrm{~W}$. The test results shown that the quality parameters evaluated were not efficient to reveal adulteration. The adulterant addition increased consumption about $7 \%$ (mass), as well increased concentrations of CO and $\mathrm{HC}$ by 38 and 16\%, respectively, despite reduction of NOx to $15 \%$.

Keywords: Distillation curve, fuel, Gasoline adulteration.
\end{abstract}




\section{INTRODUÇÃO}

A gasolina é uma mistura de hidrocarbonetos saturados, olefínicos e aromáticos com moléculas de cinco a 13 átomos de carbono e faixa de destilação entre $35^{\circ} \mathrm{C}$ e $220^{\circ} \mathrm{C}$ podendo, ainda, estar combinada a outros compostos (BORSATO; GALÃO; MOREIRA, 2009). No Brasil, conforme a aplicação, vários tipos de gasolina são oferecidos aos consumidores, entretanto, os dois tipos mais comuns são a gasolina tipo $\mathrm{A}$, isenta de álcool, e a gasolina tipo $\mathrm{C}$, composta pela gasolina $\mathrm{A}$ combinada a um percentual de Álcool Etílico Anidro Carburante (AEAC), definido em lei. A gasolina A não é vendida diretamente aos consumidores, mas entregue pelas refinarias às distribuidoras que efetuam misturas para formar a gasolina $\mathrm{C}$. As distribuidoras, por sua vez, fornecem a gasolina $\mathrm{C}$ aos postos que comercializam o combustível para utilização em qualquer motor ciclo Otto (BR DISTRIBUIDORA, 2013). O percentual de etanol adicionado à gasolina é definido pelo Ministério da Agricultura, Pecuária e Abastecimento (MAPA), na portaria 678 de 31/8/2011, a qual fixa o valor em em $20 \%$ v/v, com variação de $1 \%$. Esse percentual pode oscilar, segundo a disponibilidade de matériaprima para a produção e conforme oscilações no preço do etanol ou da gasolina no mercado interno e externo (BRASIL, 2011a; BRASIL, 2012).

No Brasil, as propriedades para controle da qualidade da gasolina automotiva "tipo C" são especificadas pela resolução da Agência Nacional do Petróleo, Gás Natural e Biocombustíveis (ANP) n. 57 de 20 de outubro de 2011 (BRASIL, 2011b). Dentre essas propriedades, a Tabela 1 apresenta aquelas que serão avaliadas neste estudo.

Tabela 1: Características para controle da qualidade da gasolina automotiva tipo C

\begin{tabular}{|c|c|c|c|}
\hline Característica & Especificação & Importância do controle & Normas \\
\hline $\begin{array}{c}\text { Cor e aspecto } \\
\text { (se isento de corantes) }\end{array}$ & $\begin{array}{l}\text { De incolor a } \\
\text { amarelada, } \\
\text { límpido e isento } \\
\text { de impurezas. }\end{array}$ & $\begin{array}{l}\text { Indica a presença de contaminantes, } \\
\text { oxidação de compostos instáveis e } \\
\text { materiais em suspensão que prejudicam o } \\
\text { funcionamento do motor }\end{array}$ & NBR 14954 \\
\hline $\begin{array}{l}\text { Teor de AEAC } \\
(\% \text { vol. })\end{array}$ & $\begin{array}{l}\text { Portaria } \\
\text { MAPA }_{\dagger}\end{array}$ & $\begin{array}{l}\text { A adição de álcool altera a octanagem e a } \\
\text { emissão de poluentes }\end{array}$ & NBR 13992 \\
\hline $\begin{array}{l}\text { Massa específica } \\
\left(\mathrm{kg} \cdot \mathrm{m}^{-3}, 20^{\circ} \mathrm{C}\right)\end{array}$ & Anotar & $\begin{array}{l}\text { Indica possíveis adulterações com } \\
\text { produtos mais leves ou mais pesados }\end{array}$ & NBR 7148 \\
\hline Destilação $\left({ }^{\circ} \mathrm{C}\right)$ & & \multirow{6}{*}{$\begin{array}{l}\text { Curva de destilação que mede as } \\
\text { características de volatilidade da gasolina }\end{array}$} & \multirow{6}{*}{ NBR 9619} \\
\hline $10 \%$ evaporado & Máximo $65^{\circ} \mathrm{C}$ & & \\
\hline $50 \%$ evaporado, & Máximo $80^{\circ} \mathrm{C}$ & & \\
\hline $90 \%$ evaporado & $\begin{array}{l}\text { Entre } 190 \text { e } \\
145^{\circ} \mathrm{C}\end{array}$ & & \\
\hline PFE, max. & $220^{\circ} \mathrm{C}$ & & \\
\hline Resíduo, \% vol. max. & 2,0 & & \\
\hline
\end{tabular}

Fonte: Brasil (2011b).

Combustíveis formados a partir de muitos compostos, como a gasolina, evaporam em diferentes temperaturas de ebulição. Nesse sentido, o conceito de curva de destilação surge devido à variação da temperatura em função do volume evaporado (FRENCH; MALONE, 2005).

Segundo Pontes (2002), devido à abertura de segmentos industriais e à competição externa na década de 1990, o governo brasileiro também flexibilizou o setor de distribuição e comercialização de derivados de petróleo, permitindo a importação de diversos produtos e a abertura de novos postos. $\mathrm{O}$ aumento na concorrência encetou práticas ilícitas, como a adição de novos compostos ou o aumento 
da concentração de compostos já presentes na gasolina $\mathrm{C}$, como o AEAC. As consequências decorrentes desses fatos são evasão fiscal, competição desleal, potenciais avarias nos motores e danos ao meio ambiente (DAGOSTIN, 2003; TAKESHITA, 2006). As principais formas de adulteração envolvem a adição de solventes derivados de petróleo, como por exemplo o Solvente para Borracha (SPB) (DAGOSTIN, 2003; JURAS, 2005), ou mesmo adição do Álcool Etílico Anidro Combustível (AEAC) além do especificado em lei. A adulteração da gasolina, seja pela adição de um novo composto ou pelo excesso de um composto já presente, provoca mudanças em suas propriedades físico-químicas e, portanto, na operação do veículo (TAKESHITA, 2006). Além da ação no veículo, existem outras consequências, relacionadas ao aumento de emissões de gases de combustão nocivos, como o $\mathrm{CO}, \mathrm{HC}$ e $\mathrm{NO}_{\mathrm{x}}$, devido à queima irregular da gasolina no motor (THARBY, 2002).

Nesse contexto, o presente trabalho propõe avaliar a influência da adição de Solvente para Borracha (SPB) na gasolina A, contendo $20 \%$ v/v de AEAC, considerando resultados obtidos a partir de parâmetros de qualidade (ensaio de destilação, teor de etanol, cor e aspecto e massa específica) e, com auxílio de um motor-gerador, de desempenho de consumo mássico e emissões dos poluentes monóxido de carbono $(\mathrm{CO})$ hidrocarbonetos $(\mathrm{HC})$ e óxidos de nitrogênio $\left(\mathrm{NO}_{\mathrm{x}}\right)$.

\section{MATERIAL E MÉTODOS}

\subsection{Misturas de combustíveis utilizadas}

Para a realização dos ensaios foi utilizado um conjunto de misturas no qual se combinou previamente gasolina A com $20 \%$ v/v de AEAC (E20) com diferentes percentuais de SBP. A gasolina A e o AEAC foram gentilmente cedidos pela Cia Ipiranga Produtos de Petróleo S.A, de Guarapuava, enquanto que o SPB foi fornecido pelo Laboratório de Pesquisa e Análise de Combustíveis da Universidade Estadual de Londrina (UEL).

As porcentagens das misturas de combustíveis foram obtidas tomando-se como referência o trabalho de Dagostin (2003). No presente trabalho, foram avaliados ensaios de destilação para as misturas contendo 10, 20, 30 e 40\% v/v de SPB na gasolina A acrescida de 20\% v/v de AEAC (aqui designadas como S10, S20, S30 e S40, respectivamente). O preparo das misturas de combustível foi realizado no Laboratório de Fluorescência e Ressonância Paramagnética de Elétrons —Laflurpe e os ensaios com o motor de combustão na Fazenda- Escola - Fazesc , ambos localizados na Universidade Estadual de Londrina - UEL. As análises dos parâmetros físico-químicos das amostras foram realizadas no Laboratório de Análise de Combustíveis da Unicentro, em Guarapuava. Inicialmente, preparou-se a mistura de gasolina A mais $20 \% \mathrm{v} / \mathrm{v}$ de AEAC procedendo-se, em seguida, a adulteração com 10, 20, 30 e 40\% v/v de SPB. Após a elaboração das misturas, a fim de evitar degradação das amostras, essas foram acondicionadas em embalagens hermeticamente fechadas, em local escuro e refrigerado.

As análises físico-químicas iniciaram com a destilação - NBR 9619 (ABNT, 2009), seguida pelas análises de teor de álcool etílico anidro combustível (AEAC) - NBR 13992 (ABNT, 1997), massa específica - NBR 7148 (ABNT, 2001) e finalmente cor e aspecto - NBR 14954 (ABNT, 2011). Todas as análises físico-químicas foram realizadas em duplicata. Os parâmetros de qualidade avaliados neste estudo para a gasolina automotiva "tipo C" são especificadas na resolução n. 57 de 20 de outubro de 2011 (BRASIL, 2011b) já reportados na Tabela 1. 


\subsection{Características e montagem dos equipamentos para os ensaios de desempenho e emissões gasosas}

Os ensaios utilizaram um motor acoplado a um gerador acrescido dos seguintes itens: painel de dissipação de energia elétrica, medidor de potência, analisador automático de emissões gasosas, balança digital de precisão e computador para aquisição dos dados.

O grupo motor-gerador, marca Toyama e modelo TG2800, é equipado com um motor monocilíndrico ciclo Otto, com deslocamento volumétrico de $196 \mathrm{cc}$, com um ciclo de quatro tempos e alimentação de combustível por carburador, o motor desenvolve potência máxima de 6,5 HP (4,85 $\mathrm{kW}$ ) a uma velocidade, controlada mecanicamente, constante de $3600 \mathrm{rpm}$. Esse motor está acoplado a um gerador, modelo síncrono, operando nesse experimento com 110 Volts e com frequência próxima de $60 \mathrm{~Hz}$, derivada da velocidade constante do motor. O gerador tem potência máxima de operação de 2,5 kW (TOYAMA, 2012).

O painel de dissipação utilizado nesse experimento tinha a função de dissipar a potência gerada pelo dínamo do gerador, desempenhando, assim, o papel de um dinamômetro. O painel de dissipação foi construído de modo a garantir cargas constantes de operação. O equipamento era composto de dez lâmpadas halógenas, de modo a configurar todos os modos de operação (cargas) utilizados neste estudo.

A amostragem e a análise das emissões gasosas, assim como o processamento das informações deu-se por meio de um analisador de gases automático, modelo TM 132 (marca Tecnomotor), tipicamente utilizado em inspeções veiculares, equipado com dispositivo infravermelho não dispersivo (NDIR) para detecção de $\mathrm{CO}$ e $\mathrm{HC}$, e sensores eletroquímicos para detecção de $\mathrm{O}_{2}$ e $\mathrm{NO}_{\mathrm{x}}$. As especificações técnicas do analisador são apresentadas na Tabela 2.

Tabela 2: Especificações técnicas do analisador automático de gases

\begin{tabular}{cccc}
\hline & \multicolumn{2}{c}{ Especificaçães técnicas } \\
Gás & Técnica de medição & Faixas de medição máximas & Resolução \\
\hline CO & NDIR & $10 \%$ vol. & $0,01 \%$ \\
HC Totais & NDIR & $20.000 \mathrm{ppm}$ vol. & $1 \mathrm{ppm}$ \\
$\mathrm{NO}_{\mathrm{x}}$ & Célula eletroquímica & $5.000 \mathrm{ppm}$ vol. & $1 \mathrm{ppm}$ \\
$\mathrm{O}_{2}$ & Célula eletroquímica & $25 \%$ vol. & $0,01 \%$ \\
\hline
\end{tabular}

Fonte: Tecnomotor (2003).

A aquisição de dados das concentrações dos gases, medidas continuamente, foi obtida pelo software Softgas (TECNOMOTOR, 2003), instalado no computador.

\subsection{Procedimento de ensaio com o motor de combustão interna}

Os ensaios tiveram como referência os estudos realizados por West et al (2008), que mencionam a norma ISO 8178, a qual especifica critérios de ensaio para determinação de emissões gasosas em motores de combustão interna. A Tabela 3 mostra os critérios de ensaio para motores ciclo Otto para dimensões de motores similares ao utilizado neste estudo, e especificados na norma (WEST et al., 2008). 
Tabela 3: Configuração para os ensaios de emissões conforme ISO 8178

Ciclos de ensaio para motores com deslocamento volumétrico entre 100 e 225

cc.

\begin{tabular}{ccccccc}
\hline Ciclo de ensaio & 1 & 2 & 3 & 4 & 5 & 6 \\
Carga [\%] & $100 \%$ & $75 \%$ & $50 \%$ & $25 \%$ & $10 \%$ & 0 \\
Carga [W] & 2400 & 1800 & 1200 & 600 & 240 & 0 \\
\hline
\end{tabular}

Fonte: Adaptado de West et al. (2008).

A Tabela 3 mostra o ciclo de ensaio e as respectivas cargas proporcionais para um motor com deslocamento volumétrico entre 100 e $225 \mathrm{cc}$, faixa em que se encontra o conjunto motor-gerador deste experimento, descrevendo ainda as cargas (em W), considerando a potência máxima de $2400 \mathrm{~W}$ para o conjunto motor-gerador deste estudo. Por recomendação do fabricante do motor-gerador, entretanto, neste trabalho optou-se por alterar a primeira carga, reduzindo-a de $2400 \mathrm{~W}$ para $2000 \mathrm{~W}$. As outras cinco cargas seguiram as especificações da norma. A literatura mostra que as emissões dos gases gerados em motores de combustão interna são diretamente proporcionais às cargas aplicadas no motor avaliado, daí a importância de variar as condições de carga (BEDOYA; ARRIETA; CADAVID, 2009; CASTELLANELLI, 2006; MIRANDA, 2007; PIPATMANOMAI; KAEWLUAN; VITIDSANT, 2009). A coleta de dados desse procedimento cobria um período de cinco minutos para cada ciclo. A cada minuto, anotava-se a variação da massa de combustível na balança, media-se a temperatura e geravam-se três relatórios de emissões. O grande número de relatório de emissões é corroborado por Hsieh et al. (2002), que atribui súbitas variações nos valores de concentração dos gases devido ao movimento recíproco de motores ciclo Otto e propõe várias coletas durante o ensaio para uma mesma carga. Assim, ao final de cada carga havia cinco medidas de consumo mássico, cinco medidas de temperatura e 15 relatórios de emissões com as concentrações de $\mathrm{CO}, \mathrm{HC}$ e $\mathrm{NO}_{\mathrm{x}}$. Esse procedimento foi repetido para os seis ciclos de ensaio (2000, 1800, 1200, 600, 240 e $0 \mathrm{~W})$, seguindo a sequência dos ciclos de ensaios apresentados na Tabela 3. Uma vez finalizado um ciclo de ensaio, trocava-se a mistura de combustível, aquecia-se o motor e um novo ciclo de ensaio reiniciava, a partir da carga de $2000 \mathrm{~W}$. Os ensaios foram executados em duplicata, iniciando com a E20 e finalizando com S40.

\subsection{Verificação do desempenho de consumo do motor}

A avaliação do desempenho de consumo do motor foi obtida mediante determinação de consumo mássico, obtido pela variação da massa de combustível na balança a cada período, com intervalos de 1 minuto conforme apresentado na Equação 1 (GAUER, 2012).

$$
\mathrm{Cm}_{\mathrm{n}}=\frac{\left(\mathrm{M}_{\mathrm{n}-1}\right)-\left(\mathrm{M}_{\mathrm{n}}\right)}{\mathrm{t}}
$$

Em que: $\mathrm{Cm}_{\mathrm{n}}$ é o consumo mássico [g. $\mathrm{min}^{-1}$ ] do período $\mathrm{n} ; \mathrm{M}_{\mathrm{n}-1}$ é a massa no início do período [g]; $\mathrm{M}_{\mathrm{n}}$ é a massa final [g] e t correspondente ao período de um minuto de ensaio [min]. Para cada ciclo de ensaio, foram anotados cinco valores $\left(n=1,2,3,4\right.$ e 5) de $\mathrm{Cm}_{n}$, cuja média resultou no consumo mássico $(\mathrm{Cm})$ para a mistura avaliada no respectivo ciclo. Esse procedimento foi feito em duplicata para as mesmas condições de carga e mistura de combustível. 


\section{RESULTADOS E DISCUSSÃO}

\subsection{Análises físico-químicas das misturas de combustíveis}

Devido à utilização das análises físico-químicas como ferramenta de físcalização contra adulteração de combustíveis, é grande o número de estudos que avaliam a eficiência desses métodos. Dagostin (2003) e Takeshita (2006) demonstraram que a maioria dos limites de controle utilizados nos testes de destilação são insuficientes para a caracterização de fraudes de adulteração da gasolina com alguns teores de adulterantes. Outros autores propuseram ferramentas estatísticas para auxiliar na identificação de ações fraudulentas (COCCO; YAMAMOTO; VON MEIEN, 2005; MENDES, 2012).

\subsubsection{Curvas de destilação}

Esta seção traz os efeitos nas curvas de destilação, inicialmente para cada um dos componentes e, em seguida, para as cinco misturas estudadas. Os resultados da Figura 1 exibem o comportamento da curva de destilação para cada um dos componentes (gasolina A, AEAC e SPB), cujos valores são exibidos na Tabela 4.

Tabela 4 - Temperaturas dos componentes para a porcentagem de volumes destilados

\begin{tabular}{ccccccccccc}
\hline & & \multicolumn{10}{c}{$\%$ destilado, $v / v$} \\
& 0 & 10 & 20 & 30 & 40 & 50 & 60 & 70 & 80 & 90 \\
& & & \multicolumn{8}{c}{ Temperaturas $\left[C^{\circ}\right]$} \\
\hline Gasolina A & 55,3 & 64,4 & 75,0 & 86,5 & 96,3 & 112,4 & 124,4 & 140,2 & 155,7 & 190,0 \\
AEAC & 74,5 & 76,9 & 76,8 & 77,7 & 77,5 & 77,5 & 77,5 & 78,6 & 77,8 & 78,0 \\
SPB & 87,3 & 88,5 & 89,5 & 90,1 & 90,4 & 91,4 & 92,8 & 93,4 & 94,8 & 97,6 \\
\hline
\end{tabular}

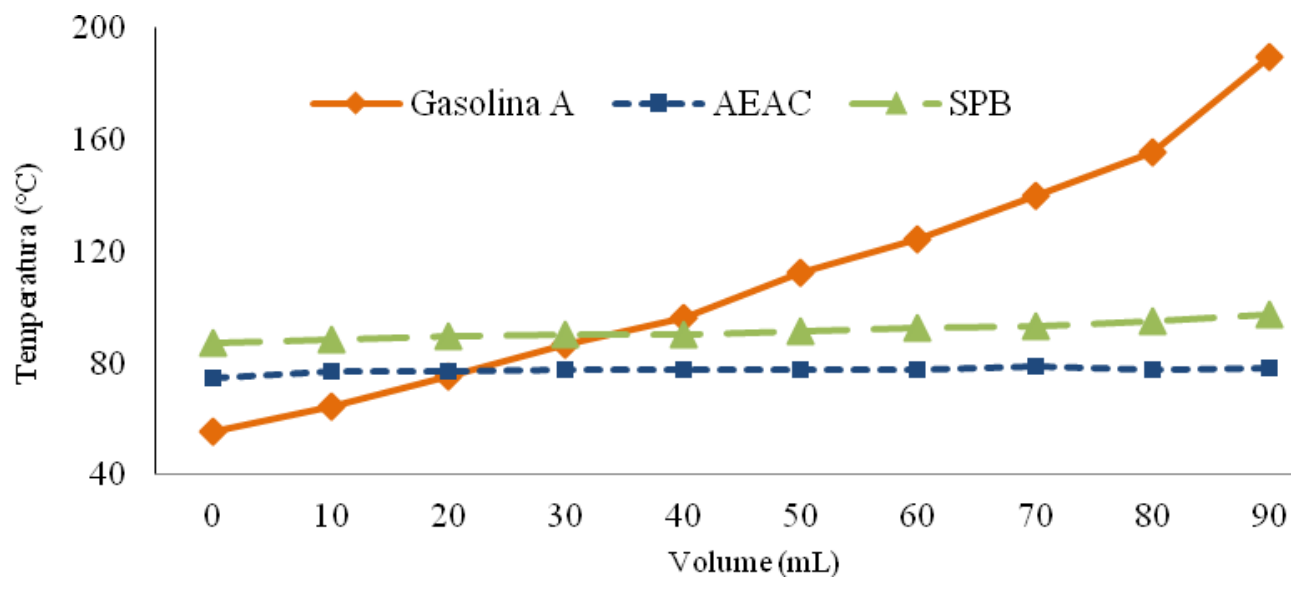

Figura 1: Curvas de destilação dos componentes 
Todas as curvas de destilação apresentam traços aproximadamente retilíneos, sem demonstrar súbitos aumentos nas temperaturas de destilação. A destilação do SPB inicia com temperatura acima do AEAC e aumenta progressivamente. Além disso, observa-se que a destilação desse componente ocorre em uma faixa com pouca variação de temperatura (entre $87^{\circ} \mathrm{C}$ e $98^{\circ} \mathrm{C}$ ).

A curva de destilação da gasolina A apresenta a maior inclinação, alcançando a temperatura de destilação do AEAC aos $23 \mathrm{~mL}$ do volume destilado, a temperatura de destilação do SPB aos $35 \mathrm{~mL}$ de volume destilado, atingindo temperaturas próximas a $190^{\circ} \mathrm{C}$ para os $90 \mathrm{~mL}$ do volume destilado. Isso ocorre porque a gasolina A é constituída basicamente por hidrocarbonetos entre quatro e 12 átomos de carbono, cuja faixa de destilação varia de 30 a $220^{\circ} \mathrm{C}$ (TAKESHITA, 2006). O SPB também é composto por hidrocarbonetos, porém com predomínio dos alifáticos leves, com cadeias carbônicas contendo de 6 a 8 átomos de carbono. Consequentemente, o SPB dispõe temperaturas de destilação inferiores, se comparado com a gasolina A e a faixa de temperatura de destilação mais estreita (MENDES, 2012; JURAS, 2005). Em contrapartida, o AEAC, por se tratar de um componente puro, dispõe de temperatura de destilação bem definida, com a curva de destilação apresentando simetria próxima a de uma linha reta e com inclinação aproximadamente igual a zero. De acordo com Perry e Green (1999), a temperatura de destilação desse composto é em torno de $78,4^{\circ} \mathrm{C}$, como pode ser verificado de fato na Figura 1, ou seja, inferior mesmo ao SPB, dada a natureza ainda "mais leve" de seus constituintes (essencialmente etanol, de peso molecular 46 g.mol ${ }^{-1}$ ).

A Figura 2 mostra as temperaturas relativas às curvas de destilação para as misturas $\mathrm{S} 10, \mathrm{~S} 20$, S30 e S40, além do E20, entre a primeira gota destilada $(0 \mathrm{~mL})$ até o volume de $100 \mathrm{~mL}$ destilados.

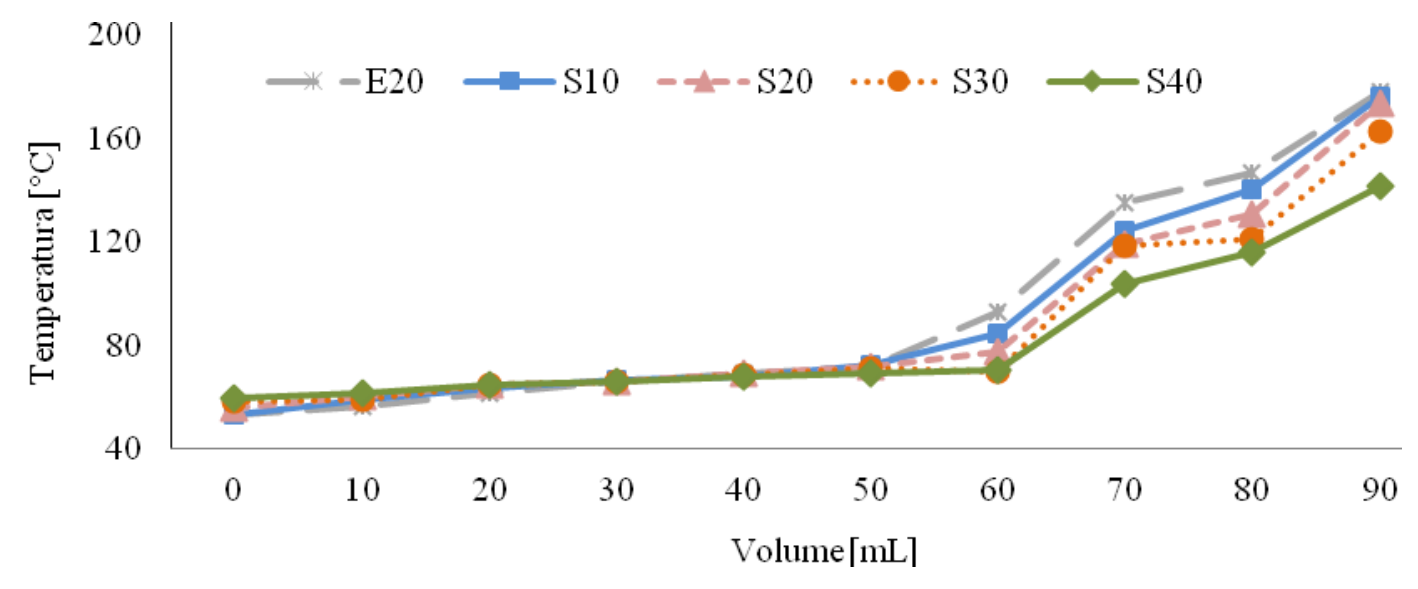

Figura 2: Curvas de destilação entre a primeira gota $(0 \mathrm{~mL})$ até $100 \mathrm{~mL}$

A primeira gota destilada indicou uma diferença de $11 \%$ na temperatura de destilação entre E20 e S40. Verifica-se que o aumento gradual de SPB nas misturas torna as temperaturas de destilação maiores para a primeira gota. Esse fato pode estar relacionado às maiores temperaturas de ebulição do SPB no início da destilação, em relação à gasolina A (Figura 1). Porém, a Figura 2 indica que para o volume de $10 \mathrm{~mL}$ destilados, nenhuma mistura contendo SPB aparece acima do limite máximo de temperatura $\left(65^{\circ} \mathrm{C}\right)$, definido em norma (BRASIL, 2011b). Da mesma forma, para $50 \mathrm{~mL}$ de volume destilados, não foram observados indícios de adulteração, já que as temperaturas permaneceram abaixo de $80^{\circ} \mathrm{C}$.

Tem-se que, quanto menor o teor de SPB na mistura, mais súbito é o aumento nas temperaturas. Quando os volumes destilados se aproximam de $90 \mathrm{~mL}$, constata-se a tendência de menores temperaturas de destilação para as misturas com maiores teores de SPB. Neste estudo, 
encontrou-se $21 \%$ de diferença nas temperaturas de destilação entre E20 e S40. A diferença já era esperada, uma vez que as temperaturas de ebulição dos hidrocarbonetos alifáticos presentes no SPB são inferiores às temperaturas de ebulição dos hidrocarbonetos que compõem a gasolina A (Figura 1). Diante do exposto, verifica-se que todos os volumes destilados mostrados na figura 2, entre $0 \mathrm{~mL}$ e 50 $\mathrm{mL}$, se apresentam em conformidade com a resolução n. 57/2011, apesar da diferença de temperatura (11\%) para a primeira gota destilada entre as misturas E20 e S40. No intuito de coibir a presença de contaminantes com menores temperaturas de ebulição, a temperatura para $90 \mathrm{~mL}$ de combustível destilado não pode ser superior a $190^{\circ} \mathrm{C}$ e inferior a $145^{\circ} \mathrm{C}$ para gasolina $\mathrm{C}$ (DIAS, 2007; BRASIL, 2011b). Durante os ensaios, as temperaturas de destilação para as misturas S10, S20 e S30 permaneceram dentro dos limites estipulados, apenas a mistura S40 apresentou temperatura de 141 ${ }^{\circ} \mathrm{C}$, inferior ao limite de $145^{\circ} \mathrm{C}$ (BRASIL, 2011b). Não obstante, este estudo indica que tal limite de temperatura não é eficiente para detectar a presença de determinadas proporções de contaminantes, pelo menos até $40 \% \mathrm{v} / \mathrm{v}$ de SPB adicionado à gasolina A acrescida de $20 \% \mathrm{v} / \mathrm{v}$ de AEAC. Os resultados de temperatura e porcentagem de combustível destilado são próximos àqueles encontrados por Dagostin (2003), nos quais a contaminação com SPB na gasolina C não foi detectada por meio dos limites estipulados para a curva de destilação. Em seu trabalho, a autora justifica isso devido ao fato do SPB evaporar em faixas de temperaturas ligeiramente superiores ao do AEAC.

A partir dos resultados obtidos neste estudo, corroborados pela literatura, verifica-se a dificuldade em determinar a adulteração de gasolina, pela legislação atual, quando misturada com teores de SPB de (até 30\% v/v) por meio da curva de destilação.

\subsubsection{Teor de AEAC}

As medidas do teor de AEAC nas misturas com SPB respeitaram as proporções, não tendo sido observadas alterações quanto às misturas preparadas com $20 \%$ v/v de AEAC.

\subsubsection{Massa específica}

As Tabelas 5 e 6 apresentam os valores encontrados para a massa específica e os desviospadrão, medidos conforme a NBR 7148 (ABNT, 2001). A Tabela 5 mostra os valores para cada componente e a Tabela 6, os valores para as misturas de gasolina A, AEAC e SPB.

Tabela 5: Valores de massa específica para cada componente

\begin{tabular}{cccc}
\hline Componentes & Gasolina A & AEAC & SPB \\
\hline $\begin{array}{c}\text { Massa específica } \\
{\left[\mathrm{kg} \cdot \mathrm{m}^{-3}\right]}\end{array}$ & $750 \pm 0,0$ & $789 \pm 0,3$ & $727,8 \pm 0,0$ \\
\hline
\end{tabular}

Tabela 6: Valores de massa específica para as misturas de gasolina A, AEAC e SPB

\begin{tabular}{ccccc}
\hline Mistura & S10 & S20 & S30 & S40 \\
\hline $\begin{array}{c}\text { Massa específica } \\
{\left[\mathrm{kg} \cdot \mathrm{m}^{-3}\right]}\end{array}$ & $752,2 \pm 0,3$ & $751 \pm 0,3$ & $750 \pm 0,0$ & $746,2 \pm 0,0$ \\
\hline
\end{tabular}

Considerando que os combustíveis fósseis são formados de hidrocarbonetos, Gibbs et al. (2009) afirmam que as variações nos valores de massa específica desses combustíveis líquidos 
geralmente são proporcionais às variações nos valores do poder calorífico. Os valores de poder calorífico superior e massa específica, por exemplo, para a gasolina são $8.325 \mathrm{kcal} . \mathrm{L}^{-1}$ e $742 \mathrm{~kg} . \mathrm{m}^{-3}$ respectivamente, enquanto que para o diesel esses valores são $9.160 \mathrm{kcal} . \mathrm{L}^{-1}$ e $852 \mathrm{~kg} \cdot \mathrm{m}^{-3}$ (BR DISTRIBUIDORA, 2013). A Tabela 5 mostra que os menores valores para a massa específica correspondem ao SPB. Esse fato pode indicar um menor poder calorífico para esse composto. Os mesmos autores destacam que isso não se aplica ao AEAC, que não é fóssil, pois apesar de apresentar maior massa específica, a presença de oxigênio na cadeia carbônica reduz o poder calorífico desse componente.

Os valores típicos para a massa específica da gasolina A acrescida de $20 \%$ v/v de AEAC (E20) não são especificados pela resolução 57 (BRASIL, 2011b), porém a faixa típica de massa específica situa-se entre 730 e $770 \mathrm{~kg} \cdot \mathrm{m}^{-3}$ (BRASIL, 2011c). Pela Tabela 6, observa-se que nenhuma mistura apresentou valores fora da faixa típica. Verifica-se, contudo, que há redução dos valores de massa específica para as misturas de combustível com o proporcional aumento do teor SPB.

\subsubsection{Cor e aspecto}

A Figura 3 exibe as cinco misturas de combustíveis (S10, S20, S30 e S40, além do E20), assim como cada um dos componentes que originaram as misturas, dispostos em tubos de ensaio para avaliação pelo método visual.

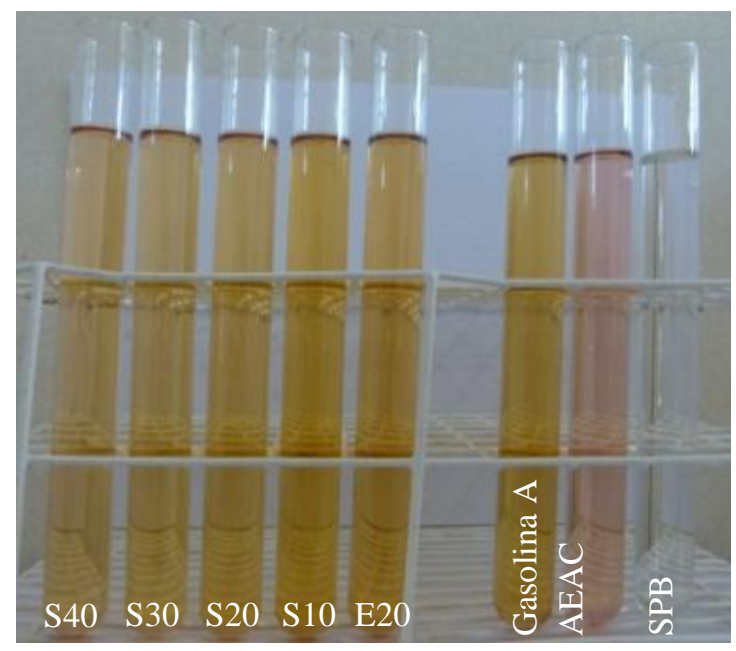

Figura 3: Cor e aspecto das misturas estudadas e componentes puros

Com a gradual adição de SPB nas amostras, verifica-se pelo método visual (ABNT, 2011), alteração na coloração das misturas de combustível, de uma tonalidade amarelada (E20) até um amarelo claro (S40). Esse fato está associado com a diluição da gasolina A pelo SPB, uma vez que as colorações dos componentes que originaram as misturas, são de tonalidade amarelada para a gasolina A e incolor para o SPB (Figura 3). Não obstante, todas as amostras apresentaram aspecto límpido e isento de impurezas. 


\subsection{Análise de desempenho para as misturas de gasolina A, AEAC e SPB}

Apesar de os ensaios de desempenho de consumo e de emissões terem sido realizados seguindo a ordem apresentada na Tabela 3 (do ciclo de ensaio 1, de $2000 \mathrm{~W}$, para o ciclo de ensaio 6, sem aplicação de carga), para favorecer a análise e discussão dos resultados, optou-se, agora, por inverter a ordem de apresentação dos dados, considerando os valores da menor para a maior carga (inicialmente 0 e, finalmente, $2000 \mathrm{~W}$ ).

A Figura 4 apresenta o consumo mássico para as misturas contendo gasolina A, AEAC e SPB (S10, S20, S30 e S40). Para fins de comparação com um combustível que respeita as especificações normativas (isento de adulteração), a Figura 4 também mostra os valores obtidos para a mistura de gasolina A e AEAC, mas sem SPB (E20).

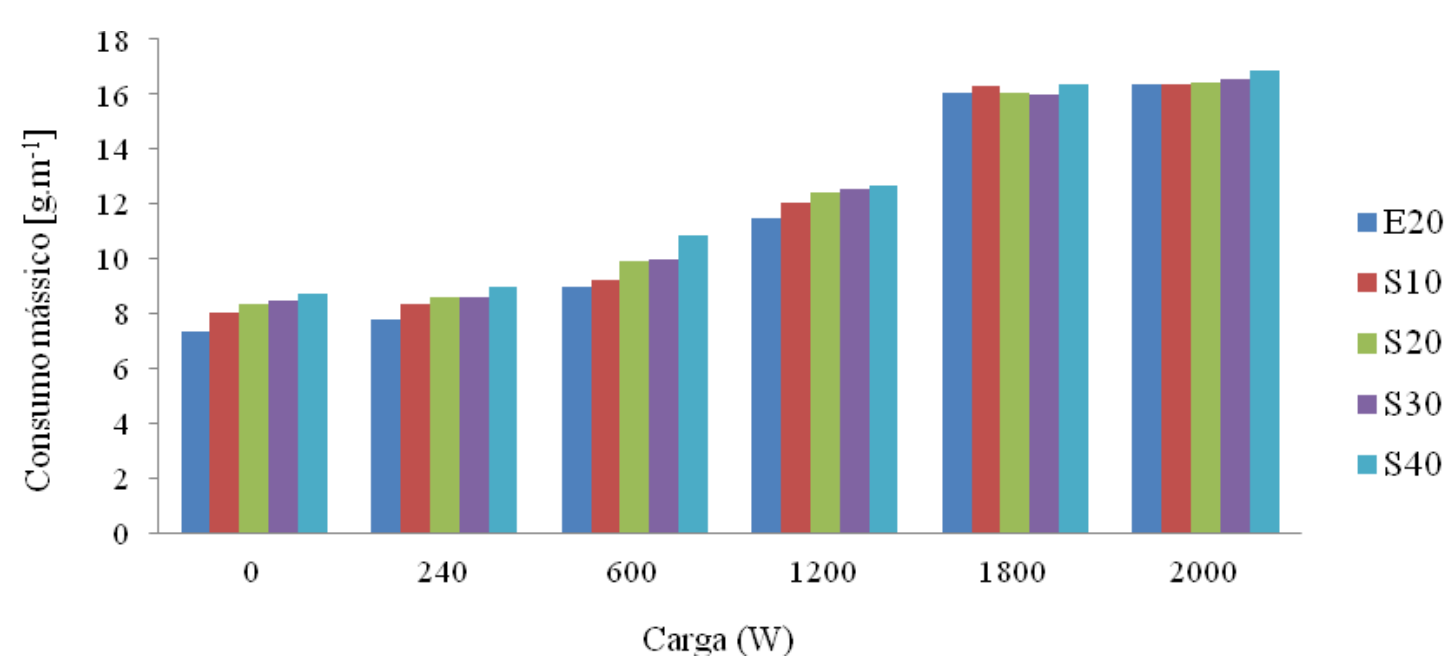

Figura 4: Cm para misturas de gasolina A, AEAC e SPB em função da carga aplicada

Vários autores citam que a adição de solventes, incluindo o SPB aumenta o consumo mássico de combustível (TAKESHITA, 2006; ALEME, 2008; LIMA; HIDALGO, 2011). Neste estudo, o consumo mássico das misturas de gasolina A, AEAC com adulterante aumentou, inclusive com a ampliação da carga. Comparando as misturas E20 e S40 para as cargas de 0, 240, 600, 1200, 1800 e $2000 \mathrm{~W}$, observa-se que o aumento de $\mathrm{Cm}$ foi $16 \%, 14 \%, 17 \%, 9 \%, 2 \%$ e 3\%, respectivamente. Em geral, esse aumento indesejável pode estar relacionado à menor massa específica do SPB (em torno de $727,8 \mathrm{~kg} . \mathrm{m}^{-3}$ ) em relação à gasolina (com valores médios de $750 \mathrm{~kg} . \mathrm{m}^{-3}$ ) e que resulta em um menor poder calorífico (GIBBS et al., 2009).

\subsection{Emissões gasosas a partir das misturas contendo gasolina A, AEAC e SPB.}

\subsubsection{Monóxido de carbono}

A Figura 5 apresenta os resultados das concentrações de CO, emitidas no escapamento do motor, para as misturas contendo gasolina A, AEAC e SPB. 
Os resultados obtidos referentes às concentrações de $\mathrm{CO}$ apresentados na Figura 5 mostram que, apesar de o teor de AEAC permanecer fixo em $20 \%$ v/v, houve variação nas concentrações de CO à medida que se aumentou o teor de SPB nas misturas, para uma mesma carga. Com exceção da mistura E20, que não apresenta SPB em sua composição, todas as outras misturas apresentaram aumento nas emissões de CO (ao se aumentar o percentual de SPB à mistura) até a carga de $600 \mathrm{~W}$, quando então as concentrações de $\mathrm{CO}$ reduziram para todas as misturas contendo SPB. Para as cargas de 1800 e $2000 \mathrm{~W}$, entretanto, as misturas com SPB apresentaram emissões de CO abaixo da mistura E20. Comparando as misturas E20 com S40, os aumentos nas emissões CO, devido aos acréscimos de SPB às misturas, foram de 39\%, 55\%, 68\% e 63\% para 0, 240, 600 e $1200 \mathrm{~W}$, respectivamente.

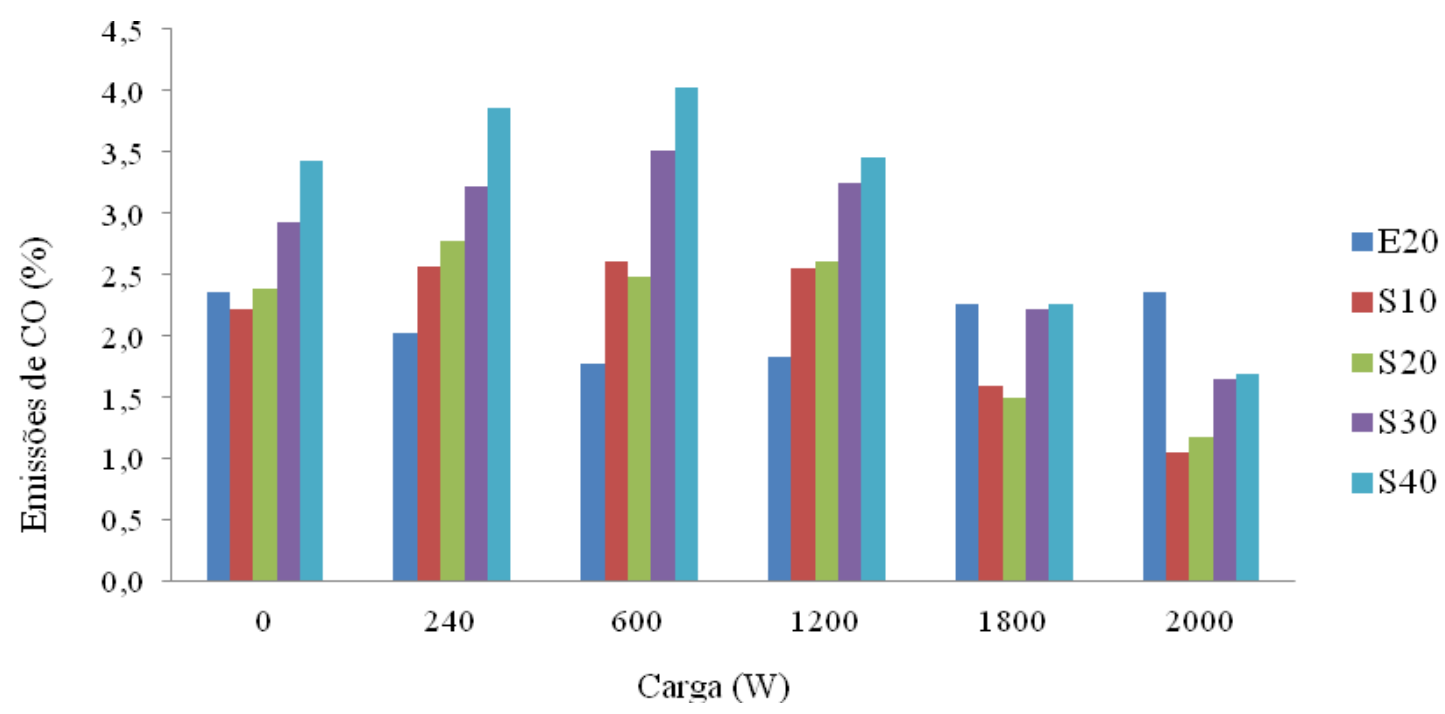

Figura 5: Emissões de CO para misturas com gasolina A, AEAC e SPB

As causas para o aumento nas concentrações de $\mathrm{CO}$ emitidas nos gases de escapamento para cargas até $600 \mathrm{~W}$ podem estar relacionadas ao aumento no consumo mássico de combustível (Figura 4) e à menor massa específica do SPB em relação à gasolina A (Tabela 5). Segundo Gibbs et al. (2009), quanto menor a massa específica de um hidrocarboneto menor o seu poder calorífico, resultando no aumento de consumo de combustível e em maiores concentrações de carbono nos gases de exaustão, uma vez que, nesse caso, a concentração do combustível oxigenado das misturas permaneceu constante em $20 \%$ v/v. No entanto, a redução nas emissões de CO, com o aumento das cargas, pode estar associada a dois fatores que atuam conjuntamente. O primeiro fator refere-se à constituição química do SPB, principalmente devido ao predomínio de alifáticos leves, formados com moléculas de menor cadeia carbônica, entre $\mathrm{C}_{6}$ e $\mathrm{C}_{8}$ (DAGOSTIN, 2003; MENDES, 2012) e que resulta em menores temperaturas de destilação, entre 52 e $128^{\circ} \mathrm{C}$ (JURAS, 2005). Já o segundo fator diz respeito ao melhor aproveitamento termodinâmico do combustível para maiores cargas (maiores temperaturas) em um motor de combustão interna (HEYWOOD, 1988). Dessa forma, as misturas de $\mathrm{SPB}$ à gasolina $\mathrm{A}$ e ao $\mathrm{AEAC}$, em conjunto com maiores temperaturas dentro da câmara de combustão, aparentemente contribuem para redução das emissões de $\mathrm{CO}$, apesar de que, para as cargas de 1800 e $2000 \mathrm{~W}$, há uma tendência de aumento nas concentrações de CO, quando maiores teores de SPB são adicionados à gasolina A com $20 \%$ v/v de AEAC. 


\subsubsection{Hidrocarbonetos}

Os valores de concentração de HC para as misturas de gasolina A, AEAC e SPB são mostrados na Figura 6.

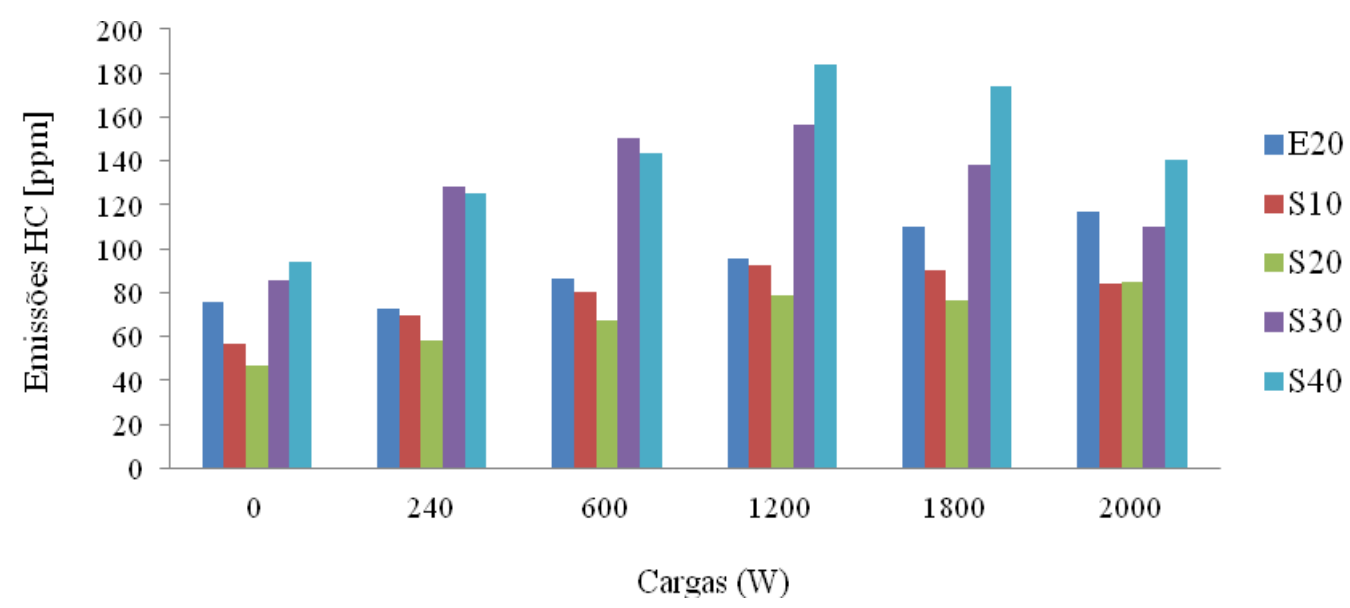

Figura 6: Emissões de HC para misturas com gasolina A, AEAC e SPB

De maneira similar à observada para as emissões de CO, constatam-se também variações nas emissões de HC, à medida que se aumentam as porcentagens de SPB nas misturas. Verifica-se que as concentrações de HC, medidas no escapamento do motor, aumentam até a carga de $1200 \mathrm{~W}$, e o aumento nas emissões de CO para a maioria das misturas ocorreu até $600 \mathrm{~W}$, quando então, iniciou a redução nas emissões de CO. A redução nas emissões de HC, iniciada após a carga de $1200 \mathrm{~W}$, parece ser menos acentuadas do que as reduções observadas para as emissões de $\mathrm{CO}$, de forma que, para as cargas de 1800 e $2000 \mathrm{~W}$, algumas misturas contendo SPB apresentam valores de HC maiores que as observadas para o E20. Comparando as misturas E20 e S40, os aumentos nas emissões HC devido aos aumentos do teor de SPB às misturas foram de 20\%, 42\%, 40\%, 48\%, 37\% e 17\% para 0, 240, 600, 1200,1800 e $2000 \mathrm{~W}$ respectivamente.

Considerando que a formação dos gases poluentes $\mathrm{CO}$ e $\mathrm{HC}$ apresentam comportamento similar (BAHR, 1972 apud CARVALHO Jr.; LACAVA, 2003; HEYWOOD, 1988), é possível presumir que, devido ao aumento no teor de SPB nas misturas de combustível, os mesmos fatores que influenciaram na formação de $\mathrm{CO}$ também podem influenciar na formação de HC. Assim, a elevação das emissões de HC até a carga de $1200 \mathrm{~W}$ também pode estar relacionado ao aumento do consumo mássico $(\mathrm{Cm})$ e à massa específica do SPB, enquanto que a redução das emissões desse gás após 1200 W pode estar associada à condição físico-química do SPB e ao melhor aproveitamento termodinâmico do combustível.

\subsection{3. Óxidos de nitrogênio}

Os valores de concentração de $\mathrm{NO}_{\mathrm{x}}$ para as misturas de gasolina $\mathrm{A}$, AEAC e SPB são mostrados na Figura 7. 


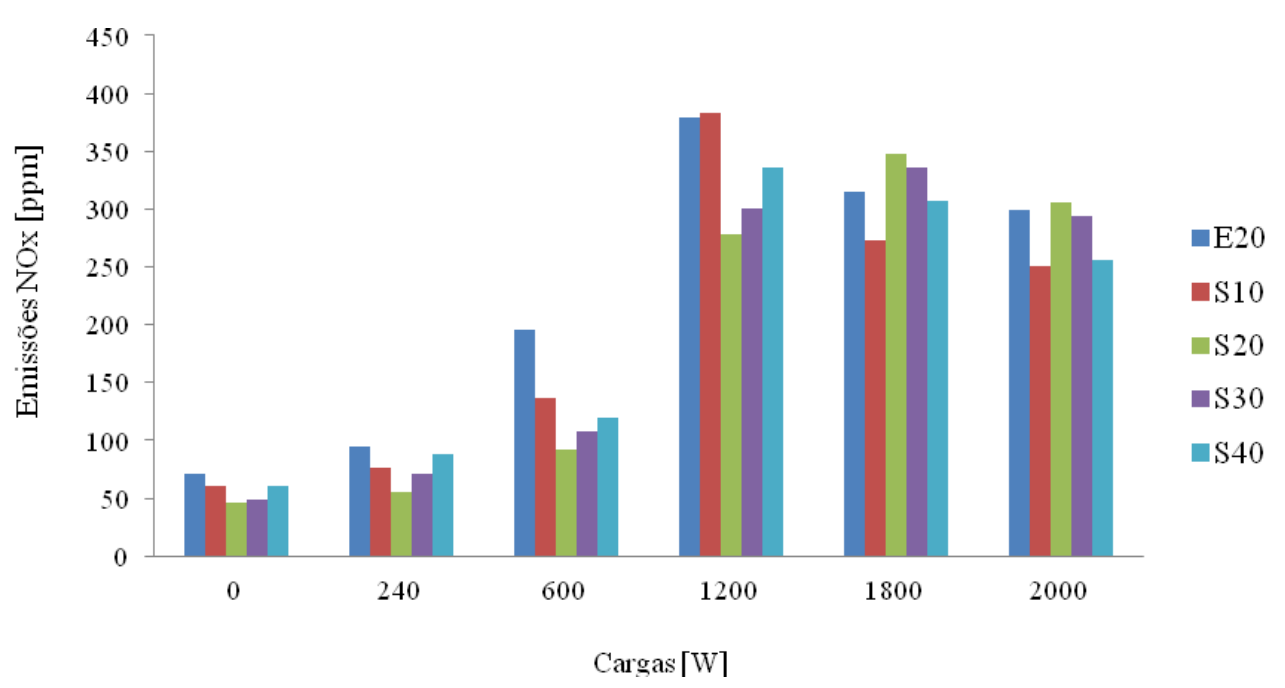

Figura 7: Emissões de $\mathrm{NO}_{\mathrm{x}}$ para misturas com gasolina A, AEAC e SPB

Conforme a Figura 7, verifica-se que as concentrações de $\mathrm{NO}_{\mathrm{x}}$, para todas as misturas contendo SPB, seguem valores com bastante variabilidade, quando tomadas como referência as emissões de $\mathrm{NO}_{\mathrm{x}}$ observadas para a mistura E20. Porém, comparando as misturas E20 e S40, constatam-se reduções nas emissões de $\mathrm{NO}_{x}$ em $18 \%, 7 \%, 64 \%, 13 \%, 3 \%$ e $17 \%$ para 0, 240, 600, 1200, 1800 e $2000 \mathrm{~W}$, respectivamente. De acordo com a literatura (HEYWOOD, 1988), a formação de $\mathrm{NO}_{\mathrm{x}}$ para uma mesma carga está intimamente ligada à variação da temperatura dentro da câmara de combustão. Como essa temperatura depende da energia fornecida pelo combustível, possivelmente está condicionada ao tipo de combustível utilizado. Neste estudo, constatou-se que a massa específica do SPB é bem menor que a da gasolina A, com $20 \% \mathrm{v} / \mathrm{v}$ de AEAC. Dessa forma, conforme afirma Gibbs et al. (2009), quanto menor a massa específica de um hidrocarboneto fóssil utilizado como combustível, menor o seu poder calorífico. Assim, é possível que a adição de SPB à mistura de combustível ocasione menores temperaturas dentro da câmara de combustão, dado o menor poder calorífico do SPB, influenciando também na redução das concentrações de $\mathrm{NO}_{\mathrm{x}}$ medidas no escapamento.

\section{CONCLUSÕES}

\subsection{Análises físico-químicas das misturas de combustíveis}

Em relação às análises físico-químicas, as temperaturas de destilação de E20 e S40 apresentaram diferenças de $11 \%$ para primeira gota e $21 \%$ para $90 \mathrm{~mL}$ destilados. Apesar disso, essa variação não foi suficiente para detectar adulteração, conforme a legislação vigente. No que concerne ao ensaio de teor de AEAC, não foram observadas alterações em relação às especificações. Para os ensaios de cor e de aspecto, houve alteração na tonalidade, de amarelada para amarelo claro, em função da adição SPB nas misturas. Contudo, as misturas permaneceram límpidas e isentas de impurezas. No caso do ensaio de massa específica, os resultados apresentaram baixa variação em todos os percentuais de mistura estudadas.

Assim, como sugestão, recomenda-se a revisão dos limites estipulados nos parâmetros de qualidade para os ensaios de curva de destilação. 


\subsection{Avaliação do desempenho de consumo do motor}

As avaliações de desempenho de consumo para a gasolina A, AEAC e SPB exibiram aumento nos seus respectivos consumos, tanto pela gradual elevação das cargas como pelo acréscimo do adulterante SPB. O maior consumo mássico pode estar correlacionado ao menor poder calorífico conferido ao SPB, devido a sua menor massa específica (em torno de $727,80 \mathrm{~kg} \cdot \mathrm{m}^{-3}$ ), em relação à gasolina (com valores médios de 750,80 kg.m ${ }^{-3}$ ).

\subsection{Emissões gasosas variando carga e combustíveis}

$\mathrm{Na}$ avaliação das emissões gasosas para cargas variáveis, verificou-se significativas alterações nas concentrações dos gases poluentes $\mathrm{CO}, \mathrm{HC}$ e $\mathrm{NO}_{\mathrm{x}}$, devido ao progressivo aumento de SPB.

No caso das emissões de CO para as misturas de gasolina A, AEAC e SPB, verificou-se que, com o aumento das cargas e com a adição gradativa de SPB às misturas, houve aumento nas emissões de $\mathrm{CO}$ até $600 \mathrm{~W}$, quando, então, para cargas superiores, observou-se decréscimo nas concentrações. Acredita-se que o aumento nas emissões até $600 \mathrm{~W}$ pode estar relacionado à elevação de consumo mássico e, também, à menor massa específica do componente adulterante. A redução nas emissões após $600 \mathrm{~W}$ pode estar relacionada à própria constituição físico-química do componente adulterante, de menor cadeia carbônica e que resulta em um melhor aproveitamento termodinâmico do motor.

Considerando que a formação de $\mathrm{CO}$ e $\mathrm{HC}$ apresentam comportamento similar, o aumento nas concentrações de $\mathrm{HC}$ também pode estar relacionado ao aumento de $\mathrm{Cm}$ e à massa específica do SPB, enquanto que a redução após a carga de $1200 \mathrm{~W}$, associa-se ao melhor aproveitamento termodinâmico do combustível ligado à característica físico-química do SPB.

Finalmente, as concentrações de $\mathrm{NO}_{\mathrm{x}}$ para as misturas contendo SPB sofreram alterações distintas daquelas observadas para o $\mathrm{CO}$ e $\mathrm{HC}$, sendo altamente dependentes da variação de temperatura. Contudo, constatou-se que as emissões de $\mathrm{NO}_{\mathrm{x}}$ foram inferiores às observadas para as misturas contendo somente AEAC (E20). Tal fato pode estar associado a menores temperaturas obtidas dentro da câmara de combustão, decorrente do tipo de combustível utilizado.

\section{REFERÊNCIAS}

ALEME, H. G. Utilização de curvas de destilação e métodos quimiométricos na previsão de origem e na determinação do teor alcoólico e massa específica da gasolina automotiva. 2008. Dissertação (Mestrado em Química) - Universidade Federal de Minas Gerais, Belo Horizonte, 2008.

ASSOCIAÇÃO BRASILEIRA DE NORMAS TÉCNICAS. NBR 13992: Gasolina automotiva - Determinação do teor de Álcool Etílico Anidro Combustível (AEAC). Rio de Janeiro, 1997.

ASSOCIAÇÃO BRASILEIRA DE NORMAS TÉCNICAS. NBR 7148: petróleo e produtos de petróleo determinação de cor, aspecto, massa específica, densidade relativa e ${ }^{\circ} \mathrm{API}$ - Método do densímetro. RJ 2001.

ASSOCIAÇÃO BRASILEIRA DE NORMAS TÉCNICAS. NBR 9619: petróleo e produtos de petróleo determinação das propriedades de destilação. Rio de Janeiro, 2009.

ASSOCIAÇÃO BRASILEIRA DE NORMAS TÉCNICAS. NBR 14954: procedimentos para avaliar a presença de contaminação por água livre ou material particulado em combustível destilado. RJ, 2011.

BAHR, D. W. Control and reduction of aircraft turbine engine exhaust emissions. In: CORNELIUS, W.; AGNEW, W. G. (Eds.) Emissions from continuous combustions systems. New York: Plenum, 1972. p. $345-$ 373. 
BEDOYA, I. D.; ARRIETA, A. A.; CADAVID, F. J. Effects of mixing system and pilot fuel quality on dieselbiogas dual fuel engine performance. Bioresource Technology, v. 100, n. 24, p. 6624-6629, Dec. 2009.

BORSATO, D.; GALÃO, O. F.; MOREIRA, I. Combustíveis fósseis: carvão e petróleo. Londrina: Editora Eduel, 2009.

BR DISTRIBUIDORA, Petrobrás Distribuidora S.A. Gasolina: 2013. Disponível em: <http://www.br.com.br/wps/portal/portalconteudo/produtos/automotivos/gasolina>. Acesso em: 1 fev. 2013.

BRASIL, Ministério da Agricultura, Pecuária e Abastecimento. Portaria n. 678 de 31 de outubro de 2011. Diário Oficial da União. Brasília, 2011a. Dispõe sobre o teor de álcool etílico anidro combustível misturado à gasolina.

BRASIL, Agência Nacional do Petróleo, Biocombustíveis e Gás Natural. Resolução n. 57 de 20 de outubro de 2011. Diário Oficial da União. Brasília, 2011b. Dispõe sobre as propriedades para controle da qualidade da gasolina automotiva "tipo C" a ser comercializado pelos diversos agentes econômicos autorizados em todo o território nacional.

BRASIL, Agência Nacional do Petróleo, Biocombustíveis e Gás Natural. Cartilha do posto revendedor de combustível. 5. ed. Rio de Janeiro: 2011c. Disponível em: <www.anp.gov.br/?dw=3796>. Acesso em: 21 ago. 2013.

BRASIL, Ministério da Agricultura, Pecuária e Abastecimento. Perfil do setor do açúcar e do álcool no Brasil. Edição para a safra 2009 e 2010. 2012. 62f. Disponível em: <http://www.agricultura.gov.br/arq_editor/file/Desenvolvimento_Sustentavel/Agroenergia/estatisticas/produca o/JUNHO_2012/Publicacoes/Perfil\%20Sucroalcoleiro\%20-\%20safra\%202009-10.pdf>. Acesso em: 21 fev. 2013.

CARVALHO Jr., J. A.; LACAVA, P. T. Emissões em processos de combustão. São Paulo: Unesp, 2003.

CASTELlANELLI, M. Desempenho de motor ciclo Diesel em bancada dinamométrica utilizando biodiesel etílico de soja. 2006. Dissertação (Mestrado em Engenharia Agrícola) - Universidade Estadual do Oeste do Paraná, Cascavel, 2006.

COCCO, L. C.; YAMAMOTO, C. I.; VON MEIEN, O. F. Study of correlations for physicochemical properties of Brazilian gasoline. Chemometrics and Intelligent Laboratory Systems, v. 76, n. 01, p. 55-63, Mar. 2005.

DAGOSTIN, A. P. D. Estudo da contaminação da gasolina com solvente para borracha. 2003. Relatório (Estágio supervisionado) - Universidade Federal de Santa Catarina, Florianópolis, 2003.

DIAS, J. A. ; MACHADO, P. A. O.; MACHADO, E. H.; DIANA, R. A. D. Entendendo a adulteração de combustíveis. 3.ed. São Paulo: 2007.

FRENCH R. E.; MALONE P. Phase equilibria of ethanol fuel blends. Fluid Phase Equilibria, v. 228-229, p. 27-40, Feb. 2005.

GAUER, M. A. Avaliação do desempenho e das emissões gasosas decorrentes do uso de biodiesel de soja e de sebo bovino em diferentes misturas com o diesel em um motor gerador. 2012. Dissertação (Mestrado em Bioenergia) - Universidade Estadual do Centro-Oeste, Guarapuava, 2012.

GIBBS, L. et al.. Motor gasolines technical review (FTR-1). Chevron Company 2009. Disponível em: <http://www.chevronwithtechron.com/products/documents/69083_motorgas_tech_review.pdf $>$. Acesso em: 2 abr. 2013. 
HEYWOOD, J. B. Internal combustion engine fundamentals. New York: McGraw-Hill, 1988.

HSIEH, W. D.; CHEN, R. H.; WU, T. L.; LIN, T. H. Engine performance and pollutant emission of an SI engine using ethanol-gasoline blended fuels. Atmospheric Environment, v. 36, n. 03, p. 403-410, Jan. 2002.

JURAS, I. A. G. M. Impacto à saúde e ao meio ambiente do aumento irregular de solventes na gasolina. Câmara dos deputados. Brasília, 2005. Disponível em: <http://bd.camara.gov.br/bd/bitstream/handle/bdcamara/1027/impacto_saude_juras.pdf?sequence=4>. Acesso em: 28 maio 2013.

LIMA, N. F. W. HIDALGO, P. F. Utilização de cromatografia gasosa na análise e controle de qualidade de combustíveis. In: ENCONTRO DE CIÊNCIA E TECNOLOGIA, 2011, III. Anais... Brasília: UnB, 2011. Disponível em: <http://observatorioderesiduos.com.br/wp-content/uploads/2012/01/ANAIS_IIIECT5.pdf>. Acesso em: 23 maio 2013.

MENDES, G. Detecção de adulterações em gasolina e previsão de parâmetros fisico-químicos a partir de curvas de destilação associadas à ferramentas quimiométricas. 2012. Tese (Doutorado em Química) Universidade Federal de Minas Gerais, Belo Horizonte, 2012.

MIRANDA, G. R. Avaliação das emissões atmosféricas provenientes da combustão do diesel, biodiesel de óleo de fritura e suas misturas. 2007. Dissertação (Mestrado em Engenharia Ambiental) - Universidade Federal de Santa Catarina, Florianópolis, 2007.

PERRY, R. H.; GREEN D. W. Perry's Chemical Engineer's Handbook. McGraw-Hill Companies, Inc. 7. ed. 1999.

PIPATMANOMAI, S.; KAEWLUAN, S.; VITIDSANT, T. Economic assessment of biogas-to-electricity generation system with $\mathrm{H}_{2} \mathrm{~S}$ removal by activated carbon in small pig farm. Applied Energy, v. 86, n. 05, p. 669-674, May. 2009.

PONTES, L. O combustível automotivo no Brasil. Qualidade e preço. Por que tanta confusão? Revista Com Ciência, SBPC/Labjor, Brasil, 2002. <http://www.comciencia.br/reportagens/petroleo/pet18.shtml>. Acesso em: 21 jan. 2013.

TAKESHITA, E. V. Adulteração de gasolina por adulteração de solventes: análise dos parâmetros físicoquímicos. 2006. Dissertação (Mestrado em Engenharia Química) - Universidade Federal de Santa Catarina, Florianópolis, 2006.

TECNOMOTOR. Manual de operação, analisador de gases TM 132. 2003. Disponível em: <http://www.tecnomotor.com.br/novo/index.php/manuais-de-produtos〉. Acesso em: 20 set. 2012.

THARBY, R. Catching gasoline and diesel adulteration. Urban Air Pollution. South Asia Urban Air Quality Management Briefing, The World Bank, Note n. 7. 2002.. Disponível em: <http://meerutup.tripod.com/diesel.pdf>. Acesso em: 26 ago. 2013.

TOYAMA. Manual de operação do gerador modelo TG2800CX. Disponível em: <http://www.toyama.com.br/imagens/produtos/manual/MA\%20TOY\%20GAS\%20GER\%20TG2800CX\%20T G4000CX\%20TG6500CX.pdf>. Acesso em: 20 set. 2012.

WEST, B.; KNOLL, K.; WENDY, C.; GRAVES, R.; ORBAN, J.; PRZESMITZKI, S.; THEISS, T. Effects of intermediate ethanol blends on legacy vehicles and small non-road engines. Oak Ridge: Oak Ridge National Laboratory, 2008. 